\title{
Safety and Efficacy of Oral Mirodenafil in Mexican with Erectile Dysfunction
}

\author{
Juan Gerardo Reyes-García1 ${ }^{*}$, Noemí Santos-Caballero², Francisco Javier Flores-Murrieta ${ }^{1,3}$ \\ ${ }^{1}$ Sección de Estudios de Posgrado e Investigación, Escuela Superior de Medicina, Instituto Politécnico Nacional, Ciudad de México, \\ Mexico \\ ${ }^{2}$ Landsteiner Scientific, S.A. de C.V., Ciudad de México, Mexico \\ ${ }^{3}$ Unidad de Investigación en Farmacología, Instituto Nacional de Enfermedades Respiratorias “Ismael Cosio Villegas”, Ciudad de México, \\ Mexico \\ Email: *juangreyesgarcia@gmail.com
}

How to cite this paper: Reyes-García, J.G., Santos-Caballero, N. and Flores-Murrieta, F.J. (2016) Safety and Efficacy of Oral Mirodenafil in Mexican with Erectile Dysfunction. International Journal of Clinical Medicine, 7, 628-638.

http://dx.doi.org/10.4236/ijcm.2016.79069

Received: June 25, 2016

Accepted: September 23, 2016

Published: September 27, 2016

Copyright $\odot 2016$ by authors and Scientific Research Publishing Inc. This work is licensed under the Creative Commons Attribution International License (CC BY 4.0).

http://creativecommons.org/licenses/by/4.0/

\begin{abstract}
Erectile dysfunction is treated with 5-phospodiesterase inhibitors as Mirodenafil, which has shown its efficacy and safety in Koreans, however; no information in other populations is available. An open clinical trial study was designed to evaluate the efficacy and safety in real life of a fixed-dose of Mirodenafil in Mexican patients with erectile dysfunction. Forty-seven male patients received a $100 \mathrm{mg}$ tablet of Mirodenafil, during 12 weeks. Primary outcome efficacy measure was the percentage of male patients with successful intercourse. Secondary outcomes measures included patient satisfaction, mood and self-esteem level. Safety assessments included laboratory tests, vital signs, physical examination, 12-lead electrocardiogram recordings, and incidence of adverse events by patients. Oral administration of Mirodenafil improved in an $80 \%-90 \%$ the number of successful intercourses from 7 to 84 days of treatment. Moreover, patients reported a significant increment in their sexual satisfaction, mood and self-esteem. Mirodenafil treatment did not modify vital signs nor anthropometric parameters during 84 days. Mild headache was the most frequent adverse event $(17.0 \%)$ and there were no severe adverse events during pharmacological treatment. Data suggest that oral Mirodenafil is safety, well tolerated and effective in the Mexican population with erectile dysfunction.
\end{abstract}

\section{Keywords}

Efficacy, Erectile Dysfunction, Mexicans, Mirodenafil, Safety

\section{Introduction}

Erectile dysfunction is defined as a consistent inability to achieve or maintain an erec- 
tion that is sufficient for satisfactory sexual intercourse [1]. Erectile dysfunction is an important worldwide health issue that has a significant negative impact on sexual satisfaction, mood and self-esteem of the affected men [1] [2]. In United States, the Massachusetts Male Aging Study reported a combined prevalence of minimal, moderate and complete impotence of $52 \%$ in subjects between 40 and 70 years [2]. In addition, a recent revision points out that more than $75 \%$ of men over 70 years old have erectile dysfunction [3]. In South Korea, the overall reported prevalence rate of dysfunction erectile is ranged between $18 \%-36.6 \%$ [1], whereas in Mexico, it is around 55\% in men over 40 years old [4]. In addition, it has been reported that incidence of erectile dysfunction is higher in men with diabetes mellitus, hypertension, high body weight, dyslipidemia, atherosclerosis or other diseases associated with endothelial dysfunction [1] [5]-[7].

The first-line of pharmacological treatment of erectile dysfunction is phosphodiesterase type 5 inhibitors. Currently, Mirodenafil, Sildenafil, Tadalafil Vardenafil, Udenafil and Avanafil belong to this pharmacological group [1] [8]. Mirodenafil is an analogue of the pyrrolopyrimidinone launched in Korea in 2007. Preclinical studies suggest that Mirodenafil enhances nitric oxide-cGMP- $\mathrm{K}^{+}$channels pathway resulting in a significant relaxation of the corpus cavernosum with the consequent penile erection [9] [10]. The pharmacokinetics of oral Mirodenafil is dose-dependent due to the saturable hepatic metabolism of this drug [11], it is primarily metabolized via hepatic cytochrome $\mathrm{P} 450$ $1 \mathrm{~A} 1 / 2,-2 \mathrm{~B} 1 / 2,-2 \mathrm{D}$ subfamily and $-3 \mathrm{~A} 1 / 2$ [12] and it reaches significantly higher Cmax and AUC values than those of sildenafil in the plasma and corpus cavernosum tissue [13].

Clinically, the first trial of Mirodenafil reported a significant improvement in the erectile function with respect to placebo group after 12 weeks of treatment. In addition, this study showed that the dose of 50 or $100 \mathrm{mg}$ of Mirodenafil was well tolerated, since the most frequent adverse events were mild and resolved spontaneously [14]. In line with these results, a recent meta-analysis performed from three randomized, double blind and placebo-controlled clinical trials with a total of 374 participants showed that Mirodenafil was more effective than placebo, and well tolerated, after 12 weeks of treatment [15]. In fact, Mirodenafil has resulted useful in the treatment of erectile dysfunction in diabetic, hypertensive and benign prostatic hyperplasia-induced lower urinary tract symptoms patients [16]-[18]. Notwithstanding, all studies have been made in Korean men and the information in other populations is lacking. Considering that ethnicity is a key factor that may modify both pharmacokinetics and pharmacodynamics of drugs, resulting in variability in response to drug therapy [19], as well as, the limited information available between Mexicans and Koreans. The current hypothesis was raised since previous studies have reported ethnic differences in allele frequencies for selected enzymes, transporters, and pharmacologic targets between White, Black and Asian populations [20]. In addition, our group has reported that some drugs metabolized by CYP3A as sildenafil, an analogue of mirodenafil, reach higher plasmatic levels in Mexicans in comparison with Whites [21]. For these reasons, we consider that it is 
necessary to perform clinical studies in different ethnic populations to rationally establish drug dosing and, if necessary, optimize its efficacy and safety for each population, especially, when the information is unknown. The current study investigated the efficacy and safety in real life of a tablet of $100 \mathrm{mg}$ of Mirodenafil per week, on an "as needed" basis in Mexican men with erectile dysfunction.

\section{Patients and Methods}

\subsection{Subjects}

A prospective, open clinical trial was performed between January and June 2011 to evaluate the efficacy and safety in real life of a $100 \mathrm{mg}$ tablet of Mirodenafil per week during 84 days, in Mexican men with erectile dysfunction. Forty-seven subjects were included in the study. All of them were between 18 and 65 years old, with erectile dysfunction for at least three months and active sexual life. In addition, no one was taking any other dysfunction erectile treatment. Exclusion criteria were subjects who had a penile anatomical problem, had undergone penile surgery or spinal cord injury, were on medication containing nitrate or nitric oxide preparations or antiandrogen therapy, had a primary diagnosis of sexual disorder different to erectile dysfunction, had alcoholism or drug addiction and had previously hypersensitive reactions to phosphodiesterase type 5 inhibitors. In addition, the health status of patients was determined by medical history, clinical examination and suitable laboratory tests as blood chemistry, hematic biometry, urinalysis and electrocardiogram. If patients had peptic ulcer, ischemic heart disease, urinary tract infection, diabetic retinopathy, diabetic neuropathy, ketoacidosis or other severe concomitant medical conditions were also excluded from the study. This study was carried out following the recommendations of the latest version of the World Medical Association Declaration of Helsinki-Ethical Principles for Medical Research Involving Human Subjects [22]. The Institutional Research and Ethics Committees of our institution approved the current protocol.

\subsection{Study Design}

All participants read the protocol and provided written informed consent for their participation in the study. After obtaining written informed consent, patients received a blister with 12 tablets of $100 \mathrm{mg}$ of Mirodenafil. Landsteiner Scientific, S. A. de C. V. (Mexico City, Mexico) provided all Mirodenafil tablets. Patients were informed about the time to onset and duration of the effects of $100 \mathrm{mg}$ Mirodenafil. Furthermore, all patients were instructed to take only a capsule of $100 \mathrm{mg}$ of Mirodenafil per week, on an "as needed" basis, one hour before sexual intercourse. All patients attended four visits. The efficacy and safety of this dose of Mirodenafil were assessed at 7 (visit 2), 42 (visit 3 ) and 84 (visit 4) days after drug treatment. General outline is shown in the Figure 1 . The primary efficacy outcome was the percentage of male patients with successful intercourse, which was assessed during each visit as the percentage of patients achieving ejaculation during all attempted sexual intercourse. The secondary efficacy outcomes were patient satisfaction, mood and self-esteem level. Patient satisfaction was 


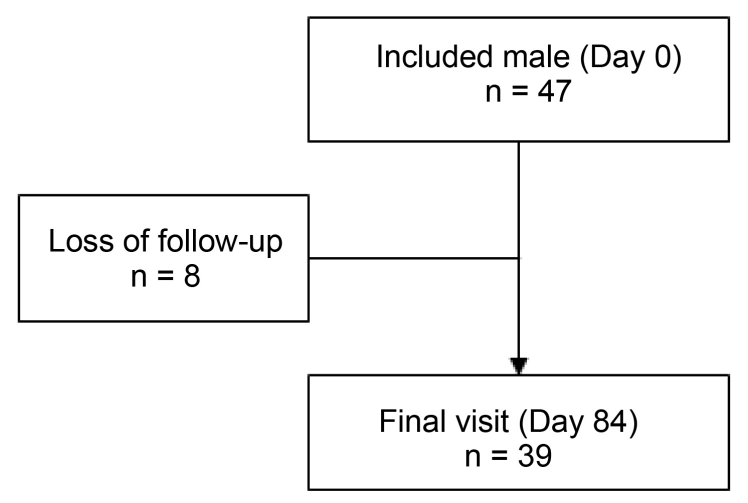

Figure 1. General outline of the study (Reyes-García et al.).

evaluated using a $10 \mathrm{~cm}$ scale without points or numbers within the scale, with exception of 0 and 10, where 0 means no satisfaction and 10 the best intercourse imaginable. The mood was assessed by the question How do you feel in your intercourse with the pharmacological treatment? and a four-point Likert scale that had the words: frustrated 1), dissatisfied 2), satisfied 3) and pleased 4); whereas the self-esteem level was evaluated using the question: How has affected your self-esteem level the pharmacological treatment?, and a second four-point Likert scale that had the words: nothing (0), very little (1), moderately (2) and definitely (3). For safety monitoring, all vital signs were assessed at baseline, and subsequently, blood pressure and heart rate were checked at every visit. Blood chemistry, hematic biometry, urinalysis and electrocardiogram were done at baseline and visit 4 (84 days). Notwithstanding, it is fair to say that in case of alarm signals to the clinical examination, the protocol contemplated earlier laboratory studies. Patients were also asked about concomitant medications and for adverse events at every visit. Causality of adverse events to the pharmacological treatment was determined by Naranjo's algorithm where more than 9 points indicates a definite causality, 5 to 8 a probable causality, 1 to 4 a possible causality and 0 is equal a doubtful causality.

\subsection{Data Analysis}

The efficacy of Mirodenafil was evaluated using a per protocol analysis based in the number of patients who completed the study. Within Mirodenafil group, statistical differences between the percentage of male patients with successful intercourse and unsuccessful intercourse in each visit was evaluated by $\chi^{2}$ test, whereas statistical analysis of the time-courses obtained from patient satisfaction, patient mood and patient selfesteem were assessed by Kruskal-Wallis' test followed by Dunn's test. Statistical significance was accepted at the $\mathrm{P}<0.05$ level. The number of patients evaluated in the current study was based on data obtained previously [16], and considering a $90 \%$ of confidence interval $(z=1.64), 80 \%$ of prevalence of success $(p), 20 \%$ of prevalence of failure (q) and $10 \%$ of precision $(d)$. According to the equation for determine a success proportion $\left(n=(Z)(p)(q) / d^{2}\right)$, and estimating a 10\% drop out, a total of 47 patients were required for efficacy analysis. Adverse events were summarized using Medical Dictio- 
nary for Regulatory Activities Preferred Terms. Change from baseline in continuous safety variables as blood pressure, heart rate and other vital signs were evaluated by Repeated Measures Analysis of Variance followed by Dunnett's test, whereas laboratory analysis and electrocardiogram parameters were assessed by a paired Student t-test.

\section{Results}

\subsection{Demographic Data}

Demographic data obtained from included male with erectile dysfunction are shown in Table 1. Volunteers were a mean \pm standard deviation (S.D.) age of $53.9 \pm 8.7$ years with a range of 31 to 65 years. In the study were included 5 patients $<40$ years and 42 patients $\geq 40$ years old. They had a sexual satisfaction of $3.32 \pm 1.5$ in the analogue visual scale (from 0 to 10 ) at the first visit. From 47 patients, 27 (57.4\%) were diabetic, 10 (21.2\%) hypertensive, 10 (21.3\%) dyslipidemic, 10 (21.3\%) smokers, and 1 (2.1\%) patient had benign prostatic hyperplasia. Respect to concomitant medications, 38 (80.9\%) were using other concomitant medications. Twenty seven (57.4\%) patients were taking hypoglycemic drugs as metformin, glibenclamide and insulin; 13 (27.6\%) were prescribed with multivitaminics as B vitamins; $10(21.2 \%)$ patients were taking antihypertensive drugs as enalapril, captopril and amlodipine among others; 9 (19.1\%) patients were using antidyslipidemic drugs as pravastatine and benzafibrate; and 10 (21.2\%) patients had other concomitant medications.

\subsection{Efficacy of Mirodenafil}

Analysis of the primary outcome efficacy measure revealed that Mirodenafil improves the percentage of male patients achieving ejaculation during intercourse, in a significant statistically manner $(P<0.05)$, from the second to the fourth visit (Figure 2$)$. In the second visit (7 days), $78.7 \%$ of male patients reported successful intercourse, whereas $88.9 \%$ (42 days) and $89.7 \%$ (84 days) of volunteers stated successful intercourse in the third and fourth visit, respectively.

Consequently, patients reported a significant increment $(P<0.05)$ in their satisfaction regarding sexual activity using a $100 \mathrm{mg}$ of Mirodenafil tablet weekly, on an "as

Table 1. Demographic data.

\begin{tabular}{cc}
\hline Characteristic & $\mathbf{n = 4 7}$ \\
Age (years) & $53.9 \pm 8.7$ \\
Weight $(\mathbf{k g})$ & $78.3 \pm 11.1$ \\
Height $(\mathrm{m})$ & $1.7 \pm 0.1$ \\
Systolic blood pressure (mmHg) & $124.8 \pm 14.3$ \\
Diastolic blood pressure (mmHg) & $76.9 \pm 11.2$ \\
Temperature $\left({ }^{\circ} \mathrm{C}\right)$ & $36.4 \pm 0.3$ \\
Heart rate (beats per minute) & $70.9 \pm 7.3$ \\
Respiratory frequency (breaths per minute) & $18.6 \pm 1.5$ \\
\hline
\end{tabular}

Data expresses the mean \pm S.D. 


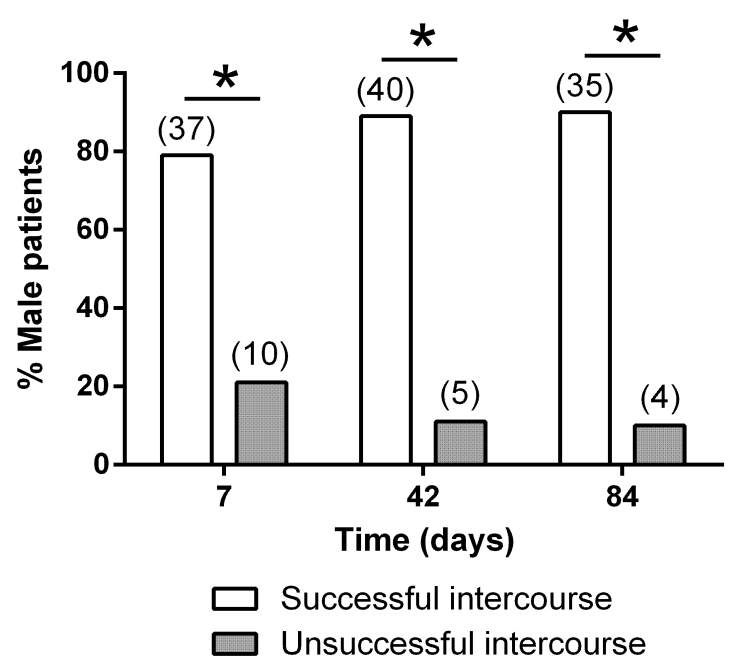

Figure 2. Percentage of male patients that reach the ejaculation during the intercourse after oral administration of a tablet of $100 \mathrm{mg}$ of Mirodenafil $(-1 \mathrm{~h})$. ${ }^{\star}$ Statistically different regarding the number of patients who did not achieve ejaculation in the same visit by $\chi^{2}$. A P < 0.05 was significant (Reyes-García et al.).

needed basis", one hour before sexual intercourse. Baseline mean \pm S.D. of sexual satisfaction was increased from $3.3 \pm 1.9$ to $6.1 \pm 2.4,7.1 \pm 2.2$ and $7.4 \pm 2.1$ at 7,42 and 84 days, respectively (Figure 3(a)). In addition, volunteers indicated that their mood after an intercourse improved from dissatisfied to satisfied during pharmacological treatment. In this regard, patients reported an average \pm S.D. basal mood of $1.8 \pm 0.6$, which was improved significantly $(\mathrm{P}<0.05)$ to $2.8 \pm 0.7,3.0 \pm 0.6$ and $3.0 \pm 0.7$ at 7,42 and 84 days (Figure 3(b)). Regarding patient's self-esteem, they reported a positive change in their self-esteem between very little and moderate at the 7 days (1.6 \pm 0.9$)$, and a positive change clearly moderate at 42 and 84 days $(2.0 \pm 1.0$ and $2.1 \pm 0.9$, respectively). The increment in the patient self-esteem was statistically different $(\mathrm{P}<0.05)$ of basal since day 7 (Figure 3(c)).

\subsection{Safety of Mirodenafil}

A tablet of $100 \mathrm{mg}$ of Mirodenafil weekly was well tolerated and safe, since only 22 patients (46.8\%) stated 34 adverse events during 84 days, and only 5 patients (10.6\%) presented 5 mild and transient adverse events definitively related to the pharmacological treatment according Naranjo's algorithm (Table 2). Adverse events related to the pharmacological treatment were tachycardia, conjunctivitis, eye irritation, facial flushing and nasal constipation. Thirty-one of total adverse events were mild (91.2\%) and 3 moderate (8.8\%). There were not severe adverse events and no patient was withdrawn from the study due adverse events. However, eight patients were lost to follow-up (Figure 1). In addition, no clinically significant changes in anthropometric parameters or vital signs were detected at every visit; consequently, laboratory tests and electrocardiogram recordings were not altered at the end of the study respect to the basal values. 


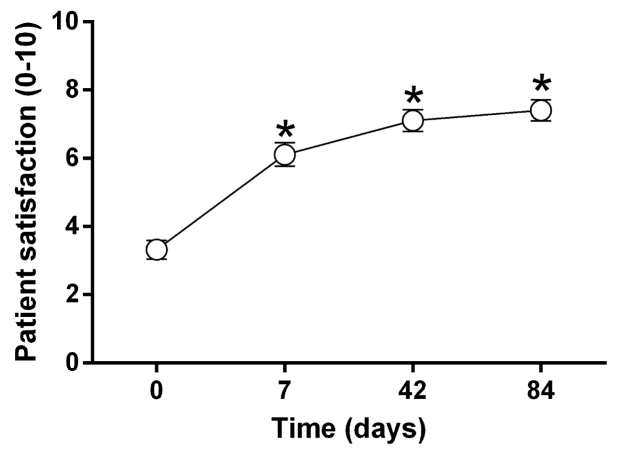

(a)

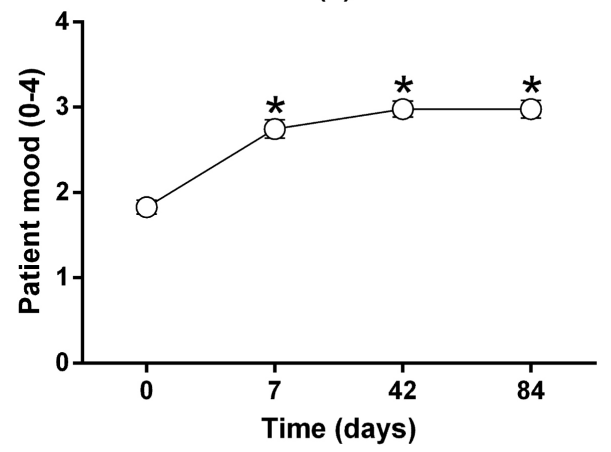

(b)

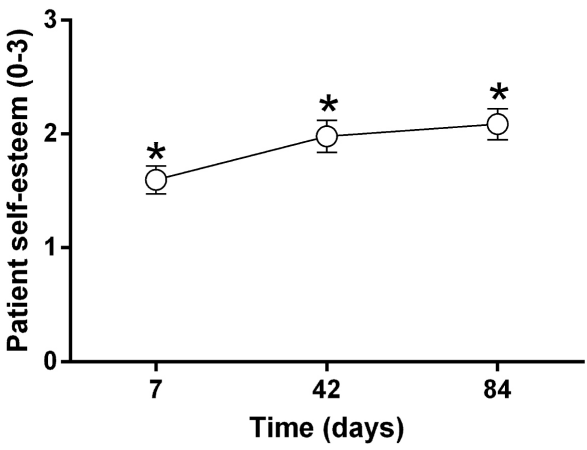

(c)

Figure 3. Improve of patient satisfaction, patient mood and patient self-esteem after oral administration of a tablet of $100 \mathrm{mg}$ of Mirodenafil 1 hour before intercourse. ${ }^{\star}$ Statistically different from basal data (day 0) by Kruskall-Wallis followed by Dunn's test. A P $<0.05$ was significant (Reyes-García et al.).

Table 2. Adverse events reported by male patients, who took a tablet of $100 \mathrm{mg}$ of Mirodenafil per week during 84 days, with an incidence greater than $3 \%$.

\begin{tabular}{cc}
\hline Adverse event & Number (\%) \\
Headache & $8(17.0)$ \\
Conjunctivitis & $2(4.3)$ \\
Eye irritation & $2(4.3)$ \\
Urinary tract infection & $2(4.3)$ \\
Total & $34(100)$ \\
Related to drug treatment & $5(14.7)$ \\
Mild & $31(91.2)$ \\
Moderate & $3(8.8)$ \\
Severe & $0(0)$
\end{tabular}




\section{Discussion}

Mirodenafil is a phosphodiesterase type 5 inhibitor developed to treat erectile dysfunction due it seems to induce a significant relaxation of the corpus cavernosum by activation of nitric oxide-cGMP- $\mathrm{K}^{+}$channels pathway [9] [10]. However, the evidence of its efficacy and safety in the treatment of erectile dysfunction is limited to Korean population [14] [15]. In this study, it was evaluated the efficacy and safety of an oral tablet of $100 \mathrm{mg}$ of Mirodenafil once a week during 84 days in a Mexican population.

Results showed that Mirodenafil increased in a significant manner the percentage of male patients reaching ejaculation during intercourse. In a similar way, the patients reported an improvement in their sexual satisfaction, as well as a moderate increment in their self-esteem and mood with the oral administration of Mirodenafil. Our data agree with a multicenter, randomized, double-blinded, placebo-controlled study performed in 223 subjects, who took placebo or fixed doses of $50 \mathrm{mg}$ or $100 \mathrm{mg}$ of Mirodenafil for 12 weeks on an "as needed" basis. In this study, authors demonstrated that Mirodenafil in both doses was superior to placebo since it showed a greater improvement in the whole sexual life of patients including erectile function, orgasmic function, sexual desire and intercourse satisfaction [14]. Similarly, a second placebo-controlled study performed in 180 subjects showed that the daily administration of $50 \mathrm{mg}$ of Mirodenafil during 12 weeks increases the rate of successful intercourse [23]. In fact, a recent meta-analysis study from three randomized controlled trials concluded that mirodenafil was well tolerated and more effective than placebo after 12 weeks [15]. In this regard, the current study extends the observations made about effectiveness of Mirodenafil in the treatment of dysfunction erectile in Korean male to Mexican male.

The risk of erectile dysfunction increases in patients with diabetes, hypertension, hyperlipidemia, tobacco use and urinary tract disorders, among other factors [5] [24]. In our study, Mirodenafil demonstrated to be effective and well tolerated in a heterogeneous Mexican population, where more than $50 \%$ of volunteers were diabetic; furthermore, around one-fifth were hypertensive, one-fifth dyslipidemic, one-fifth smokers and one patient had benign prostatic hyperplasia. According with our results, a double-blind study performed in 112 Korean diabetic male showed that $100 \mathrm{mg}$ of Mirodenafil "as needed" basis had greater improvements in sexual life and partner relationship than the placebo group [16]. In a similar way, another double blind study conducted in 109 patients taking antihypertensive drugs exhibited a greater efficacy in the $100 \mathrm{mg}$ of Mirodenafil group, compared with the placebo group, in sexual function [17]. Furthermore, Mirodenafil, not only improve sexual function in patients with benign prostatic hyperplasia, but also, the lower urinary tract symptoms associated to benign prostatic hyperplasia when it was administered concomitantly with a $\alpha_{1}$-blocker as tamsulosin and alfuzosin [18]. Moreover, some studies have demonstrated the efficacy of Mirodenafil in heterogeneous Korean populations with erectile dysfunction and associate risk factors as hyperlipidemia, tobacco use, alcohol consumption, benign prostatic hyperplasia, diabetes mellitus and hypertension [14] [16] [17] [23]. In summary, Mirodenafil seems to be effective in patients with erectile dysfunction and associated 
risk factors. Likewise, our study extends this conclusion to Mexican population.

The effectiveness of Mirodenafil in the treatment of erectile dysfunction seems obey to the activation of the nitric oxide-cGMP- $\mathrm{K}^{+}$channels pathway since its chemical structure is very similar to other phosphodiesterase 5 inhibitors [9]. In this regard, a preclinical study performed in the rat model of cavernosal nerve injury showed that Mirodenafil chronic administration was able to increase the levels of nitric oxide synthase and cGMP, as well as, to improve intracavernosal pressure of rats with cavernosal nerve injury [10].

Regarding Mirodenafil safety and tolerability, in the current study, 34 adverse events were reported during 84 days, and only five mild and transient adverse events were related to the pharmacological treatment. From total adverse events, headache was the most frequent adverse event. In line with our results, other studies have reported that Mirodenafil between $50 \mathrm{mg}$ and $150 \mathrm{mg}$ is well tolerated with a few mild or moderate total adverse events, being the headache and flushing the most common adverse events [9] [14]-[17] [23].

Furthermore, in our study, Mirodenafil seems to have good tolerability in patients who receive concomitant medications, since there were no clinically significant changes in their laboratory tests, anthropometric parameters, vital signs and electrocardiogram recordings at the end of the study. According with our results, Mirodenafil has been well tolerated in clinical trials where patients was taking concomitantly antidiabetic, anti-hypertensives or $\alpha_{1}$-blockers [16]-[18]. The current study confirms the observations above mentioned and, extends these observations to concomitant administration of Mirodenafil with multivitamins, antidyslipidemic and some analgesic drugs as acetylsalicylic acid, acetaminophen, naproxen and indomethacin.

\section{Conclusion}

In conclusion, the data suggest that Mirodenafil is effective, safety and well tolerated in the treatment of erectile dysfunction in Mexican male with erectile dysfunction. However, clinical trials in other populations with larger cohorts and long-term follow up are necessary to generalize the Mirodenafil efficacy and safety worldwide.

\section{Acknowledgements}

Authors kindly akcnowlegde Landsteiner Scientific, S.A. de C.V., Mexico City, Mexico for the formulations provided for this study.

\section{Conflict of Interest}

NS-C works in Landsteiner Scientific, S.A. de C.V., as medical director. Authors declare that there is no any other conflict of interest.

\section{References}

[1] Park, K., Hwang, E.C. and Kim, S.O. (2011) Prevalence and Medical Management of Erectile Dysfunction in Asia. Asian Journal of Andrology, 13, 543-549. 
http://dx.doi.org/10.1038/aja.2010.131

[2] Feldman, H.A., Goldstein, I., Hatzichristou, D.G., et al. (1994) Impotence and Its Medical and Psychosocial Correlates: Results of the Massachusetts Male Aging Study. The Journal of Urology, 151, 54-61.

[3] Mola, J.R. (2015) Erectile Dysfunction in the Older Adult Male. Urologic Nursing, 35, 87-93.

[4] Ugarte y Romano, F. and Barroso-Aguirre, J. (2001) Prevalencia de disfunción eréctil en México y factores de riesgo asociados. Revista Mexicana de Urología, 61, 63-76.

[5] Chitaley, K., Kupelian, V., Subak, L., et al. (2009) Diabetes, Obesity and Erectile Dysfunction: Field Overview and Research Priorities. The Journal of Urology, 182, S45-S50. http://dx.doi.org/10.1016/j.juro.2009.07.089

[6] Maas, R., Schwedhelm, E., Albsmeier, J., et al. (2002) The Pathophysiology of Erectile Dysfunction Related to Endothelial Dysfunction and Mediators of Vascular Function. Vascular Medicine, 7, 213-225. http://dx.doi.org/10.1191/1358863x02vm429ra

[7] Feldman, H.A., Johannes, C.B., Derby, C.A., et al. (2000) Erectile Dysfunction and Coronary Risk Factors: Prospective Results from the Massachusetts Male Aging Study. Preventive Medicine, 30, 328-338. http://dx.doi.org/10.1006/pmed.2000.0643

[8] Park, H.J., Moon, K.H., Lee, S.W., et al. (2014) Mirodenafil for the Treatment of Erectile Dysfunction: A Systematic Review of the Literature. The World Journal of Men's Health, 32, 18-27. http://dx.doi.org/10.5534/wjmh.2014.32.1.18

[9] Cho, M.C. and Paick, J.S. (2016) A Review of the Efficacy and Safety of Mirodenafil in the Management of Erectile Dysfunction. Therapeutic Advances in Urology, 8, 100-117. http://dx.doi.org/10.1177/1756287215625408

[10] Kim, H., Sohn, D.W., Kim, S.D., et al. (2010) The Effect of Mirodenafil on the Penile Erection and Corpus Cavernosum in the Rat Model of Cavernosal Nerve Injury. International Journal of Impotence Research, 22, 291-297. http://dx.doi.org/10.1038/ijir.2010.19

[11] Choi, Y.H., Lee, Y.S., Bae, S.H., et al. (2009) Dose-Dependent Pharmacokinetics and FirstPass Effects of Mirodenafil, a New Erectogenic, in Rats. Biopharmaceutics \& Drug Disposition, 30, 305-317. http://dx.doi.org/10.1002/bdd.669

[12] Choi, Y.H., Lee, Y.S., Lee, M.G., et al. (2010) Pharmacokinetics of Mirodenafil, a New Erectogenic, and Its Metabolite, SK3541, in Rats: Involvement of CYP1A1/2, 2B1/2, 2D Subfamily, and 3A1/2 for the Metabolism of Both Mirodenafil and SK3541. Journal of Pharmaceutical Sciences, 13, 93-106. http://dx.doi.org/10.18433/J3688M

[13] Lee, S.K., Kim, Y., Kim, T.K., et al. (2009) Determination of Mirodenafil and Sildenafil in the Plasma and Corpus Cavernous of SD Male Rats. Journal of Pharmaceutical and Biomedical Analysis, 49, 513-518. http://dx.doi.org/10.1016/j.jpba.2008.11.004

[14] Paick, J.S., Ahn, T.Y., Choi, H.K., et al. (2008) Efficacy and Safety of Mirodenafil, a New Oral Phosphodiesterase Type 5 Inhibitor, for Treatment of Erectile Dysfunction. The Journal of Sexual Medicine, 5, 2672-2680. http://dx.doi.org/10.1111/j.1743-6109.2008.00945.x

[15] Du, W., Li, J., Fan, N., et al. (2014) Efficacy and Safety of Mirodenafil for Patients with Erectile Dysfunction: A Meta-Analysis of Three Multicenter, Randomized, Double-Blind, Placebo-Controlled Clinical Trials. Aging Male, 17, 107-111. http://dx.doi.org/10.3109/13685538.2013.858114

[16] Park, H.J., Choi, H.K., Ahn, T.Y., et al. (2010) Efficacy and Safety of Oral Mirodenafil in the Treatment of Erectile Dysfunction in Diabetic Men in Korea: A Multicenter, Randomized, Double-Blind, Placebo-Controlled Clinical Trial. The Journal of Sexual Medicine, 7, 2842-2850. http://dx.doi.org/10.1111/j.1743-6109.2010.01888.x 
[17] Paick, J.S., Kim, J.J., Kim, S.C., et al. (2010) Efficacy and Safety of Mirodenafil in Men Taking Antihypertensive Medications. The Journal of Sexual Medicine, 7, 3143-3152. http://dx.doi.org/10.1111/j.1743-6109.2010.01926.x

[18] Lee, J.Y., Cho, S.Y., Oh, C.Y., et al. (2011) Efficacy and Safety of Combination Therapy with Mirodenafil and $\alpha_{1}$-Blocker for Benign Prostatic Hyperplasia-Induced Lower Urinary Tract Symptoms Accompanied by Erectile Dysfunction: A Multicenter, Open-Label, Prospective Study. International Journal of Impotence Research, 23, 249-256.

http://dx.doi.org/10.1038/ijir.2011.34

[19] Preissner, S.C., Hoffmann, M.F., Preissner, R., et al. (2013) Polymorphic Cytochrome P450 Enzymes (CYPs) and Their Role in Personalized Therapy. PLoS One, 8, Article ID: e82562. http://dx.doi.org/10.1371/journal.pone.0082562

[20] Yasuda, S.U., Zhang, L. and Huang, S.M. (2008) The Role of Ethnicity in Variability in Response to Drugs: Focus on Clinical Pharmacology Studies. Clinical Pharmacology \& Therapeutics, 84, 417-423. http://dx.doi.org/10.1038/clpt.2008.141

[21] Flores-Murrieta, F.J., Castañeda-Hernández, G., Granados-Soto, V., et al. (2000) Increased Bioavailability of Sildenafil in Mexican Men. JAMA, 283, 1826-1826.

http://dx.doi.org/10.1001/jama.283.14.1825

[22] World Medical Association Inc. (2013) Declaration of Helsinki-Ethical Principles for Medical Research Involving Human Subjects. http://www.wma.net/en/30publications/10policies/b3/

[23] Chung, J.H., Kang, D.H., Oh, C.Y., et al. (2013) Safety and Efficacy of Once Daily Administration of $50 \mathrm{mg}$ Mirodenafil in Patients with Erectile Dysfunction: A Multicenter, Double-Blind, Placebo Controlled Trial. The Journal of Urology, 189, 1006-1013. http://dx.doi.org/10.1016/j.juro.2012.08.243

[24] McCabe, M.P., Sharlip, I.D., Lewis, R., et al. (2016) Risk Factors for Sexual Dysfunction among Women and Men: A Consensus Statement from the Fourth International Consultation on Sexual Medicine 2015. The Journal of Sexual Medicine, 13, 153-167. http://dx.doi.org/10.1016/j.jsxm.2015.12.015

\section{Submit or recommend next manuscript to SCIRP and we will provide best service for you:}

Accepting pre-submission inquiries through Email, Facebook, LinkedIn, Twitter, etc. A wide selection of journals (inclusive of 9 subjects, more than 200 journals)

Providing 24-hour high-quality service

User-friendly online submission system

Fair and swift peer-review system

Efficient typesetting and proofreading procedure

Display of the result of downloads and visits, as well as the number of cited articles Maximum dissemination of your research work

Submit your manuscript at: http://papersubmission.scirp.org/

Or contact ijcm@scirp.org 